\title{
Risk analysis for the road transportation of hazardous chemicals in Malaysia: a methodology
}

\begin{abstract}
Quantitative risk analysis was recognized as a proper method for assessing the risk level of a hazardous activity, however, when this technique is applied to a transport case, there were several parameters and assumptions need to be considered before starting the Transportation Risk Analysis (TRA) calculation. This paper aims to describe how the modified TRA methodology is used for predicting the accident scenarios and their impact to humans and environment. The analytical technique was applied to a case study of liquefied petroleum gas (LPG) by road tankers. The transportation of LPG via five existing routes was studied in detail, and the corresponding societal risk were evaluated and compared.
\end{abstract}

Keyword: Accident; Risk analysis; Transportation; Methodology 